\title{
What Future for Specialized Teachers for Support Activities?
}

Irene Salmaso

PhD in Quality of Education University of Florence, Primary School teacher support

\begin{abstract}
The article examines the training of specialized teachers for support activities starting from L. 517/977, the milestone of Italian school integration, to the establishment of the Bachelor's Degree in Primary Education Sciences until it comes to the Decree on Good School and Law Proposal C-2444. The trained teacher for support activities must have the capacity to collaborate to fully involve pupils with disabilities together with curriculum teachers, with co-responsibility and sharing of all pupils.
\end{abstract}

Keywords: specialized teacher, inclusion, training

\section{Introduction}

\section{The origins of school integration in Italy}

Integration or, to a lesser extent, the educational, social, and even in-person inclusion of disadvantaged people today seems to be a milestone. In fact, much has been done in the 20th century from a legislative and social point of view over the previous centuries, but much more must be done by operators such as institutions and public bodies, teachers, educators, voluntary associations and family members of people with disabilities. Getting more and more goals appropriate to full inclusion in social and relational life with others.

As Trisciuzzi points out, the school is an institution that coincides with its function, that is, education transmits ways of doing, tools, experiences, behaviors and attitudes, ways of being and feeling, as well as knowledge, so in a word transmits Of the "values" that society finds useful or essential to the continuity of culture, and therefore school is the place that society has devoted to the transmission of basic knowledge about culture.

According to this premise, Trisciuzzi states, the insertion into the culture and the society of the person who was defined until not long ago handicapped, was a problem in ancient and medieval society and therefore was not even taken into account.

The acceptance, integration of the handicapped person in every historical period has been linked to the social conception of the handicap.

The first law of our republican order to address the problem of the invalids of disabled people in public schools was L. 118 of March 30, 1971, which thus enunciated art. 28:

"Obligatory education must take place in normal public school classes, except in cases where subjects are suffering from serious intellectual deficiencies or physical disabilities to prevent or make it difficult to learn or insert in the above mentioned normal classes".

Faced with an entry that was suddenly becoming overwhelming, the Ministry decided to set up a Commission to respond to the educational effort that the school was doing.

The document is named after the then Vice-President of the Standing Committee on Public Education, Franca Falcucci, and was drafted in 1975.

This document has taken a very important step towards school integration in Italy, as in the final report on school problems of disabled pupils, a new way of being in school was sought, more attentive to the potential and the different ways of learning Of pupils as a condition for the full integration of pupils with disabilities. 
The Falcucci document, besides representing a genuine social, cultural and pedagogical revolution, marked the official awareness of the educational problems of disabled persons by the Ministry, which, in a very timely manner, issued Circular No. 8 August 1975. 227, "Interventions in favour of disabled pupils: program for the school year 1975/76", which led to a serious awareness of the need to make an effective contribution to the solution of the problem:

"The complexity and severity of the structural and organizational problems to be solved [...] in action in the school and social integration of the aforementioned pupils are not concealed, but that is why concrete times and forms of meaningful interventions have to be studied [...] for the high democratic value that the school integration of disabled pupils has. Integration that requires a new way of being in the school. "

Thus, in the 1975/76 school year, disabled children began to be included in normal classes, abandoning special classes and differential classes; In reality, as I mentioned earlier, there was a "wild insertion" as disadvantaged students were put into classes in a precipitous way without having first thought of adequate programming for their integration.

Thus, we come to the Law which is defined as the milestone for the social and educational integration of children with disabilities: L. n. 517 of 4 August 1977.

First of all, in this law, the term insertion is replaced by the integration term, definitively sanctioning that concept also from the normative point of view.

The real purpose is not to put the boy in a different way with the normodotates in the same class making them live together, but his integration, that is, the complete inclusion in the group of peers. To do this, the teachers have the task of working together the children together, playing them together, sending non-assistive spirit to the well-informed children, but relational emotional involvement with disabled comrades. ${ }^{1}$

Integration should be considered a process of change, modification of the organizational structure of curricula and programs, leading to a new awareness of teaching professionalism, and leads to a modification of the architectural structure of schools.

Integration should be considered a process of change, modification of the organizational structure of curricula and programs, leading to a new awareness of teaching professionalism, and leads to a modification of the architectural structure of schools.

Law 517 still remains the most advanced model in the European and world domains, constitutes a definite change in the quality of schooling; From the school made by the single teacher, you go to the school made by the faculty college, from the traditional school only made to the students who are classed at the school of all.

At this point the role of who is now called a support teacher comes into play; It is necessary to redefine the training and reform of the staff, whether lecturer or non-teaching, whether specialized or not, both of the state employees and of the Local Authorities, that is, of all those whom the Law calls somehow to work for disabled children Inserted in the common classes.

The current support teacher as a historical reference is the special teacher working in special schools and then in the differential classes, and from the time when there was full inclusion of children with disabilities in the school, the support teacher has Assumed the role of contiguity with curriculum teachers.

Initially, the old high school courses and the special schools for educators for blind and deaf boys were set up, courses that could be considered serious as qualifying for the profession that then went to special teachers.

Subsequently, courses on the physiopathology of physical and psychic development were established, but they were improvised and unformed, so they were suppressed by D.P.R. n. 970/1975 Establishment of biennial training schools for staff to be handicapped. However, these courses only began in the 1979/80 school year, following the adoption of the program implementation regulation, thanks to D.M. 3/6/1977 and with the next O.M. 16/11/1977 n. 303. The first graduates of these courses entered service in the 1980/81 school year.

\footnotetext{
${ }^{1}$ N. D'Amico, History and stories of the Italian school. From Origins to Today, Zanichelli Editore, Bologna, 2010.
} 
It should therefore be hoped that new teaching staff will be formed with a real experimental mentality, that is, they should be able to experiment permanently, check and verify their work with the students scientifically. Only then could it be possible to produce good supporters with a reflexive capacity for their professionalism and experimentation in the teaching methodologies to be offered to their pupils.

It was a very long and tiring journey. Even today, society is behind the cultural societal legacy of looking at disabled children as "other" children by lawmakers, and this sometimes goes back to school where support teachers are not always considered as assigned to the class, and not to the child who will have to Follow for the duration of the school year. Since it is inserted in a given context it should be considered as a class child who needs further support to the rest of the class. ${ }^{1}$

With Law no. 270 of May 20, 1982, of the Bodrato period, it is envisaged extending to the nursery of the regulations on the reception of disabled children that had already been applied by Law 517/77 to elementary school.2

It was planned to update the number of support posts for nursery, elementary and middle school children with disabilities in order to ensure a ratio of about one support teacher to every four disabled children. It was also planned to review the recruitment procedures for teaching staff in nursery, elementary and middle school orders. ${ }^{3}$

The legislation of these years has led to a full inclusion of pupils with disabilities in the common school and at the end of the special schools, even though the school was not yet ready for cultural, organizational and methodological reasons. We begin to evaluate not only the aspect of integration of the handicapped child but the needs of the child himself in the context of social life. This means that you begin to think, more concretely than in the past, that the school does not have to worry about inclusion in the school environment but also what will happen outside the school, in the context of the child's future life He will become a teenager and adult to join the work world with his "own life project". ${ }^{4}$

For the first time in Italy in 1982 he became Minister for Public Education a woman, Franca Falcucci (December 1, $1982-$ $27,1987)$. Just to her, her tenacity and her tireless sense of duty with regard to the work she carried out, we have the reforms that the Italian school has been waiting for for fifteen years of long battles and discussions in Parliament that never came to end in the laws. ${ }^{5}$

So we arrive at Ministerial Circular no. 258 of September 22, 1983, which provides the lines of agreement between school, local authorities and USL to achieve better school integration of disabled pupils. These lines of intent are aimed at implementing common goals such as the identification of the handicap and related attestations, the programming of the Individual Education Plan, the prevention of discomfort and disadvantage, the orientation for continuing the studies and training Of operators. For the first time, we talk about collaboration between several people, the establishment of a "working group" that is responsible for coordinating projects and interventions with pupils. ${ }^{6}$

With D.P.R. n. 104 of February 12, 1985, the new Elementary School programs for the past thirty years have been issued (D.P. 503, June 14, 1955).

However, they are considered "experimental" and will come into force progressively from the 1987/88 school year. The experimental phase and the definitive entry into force occurred with Law no. 148 of 5 June 1990, whose articles were subsequently incorporated in the Single Text of the School Laws in D.L.vo no. 297/94. In the general premise there is an explicit reference to the integration of disabled pupils and learning difficulties.

With D.P.R. n. 104 of February 12, 1985, the new Elementary School programs for the past thirty years have been issued (D.P. 503, June 14, 1955).

\footnotetext{
${ }^{1}$ L. Trisciuzzi, Disability Education Manual, Laterza, Bari, 2010.

2 P. Bosio, I. Menegoi Buzzi, (ed.), School and Diversity in Europe. Teacher Training Tools on Integrating Disabled in School, FrancoAngeli, Milan, 2005.

${ }^{3}$ See N. D'Amico, History and Stories ... op. cit.

${ }^{4}$ P. Bosio I. Menegoi Buzzi, (ed.), School and Diversity in Europe .... op. cit.

${ }^{5}$ See N. D'Amico, History and Stories ... op. cit.

${ }^{6}$ See P. Bosio I. Menegoi Buzzi, (ed.), School and Diversity in Europe .... op. cit.
} 
However, they are considered "experimental" and will come into force progressively from the 1987/88 school year. The experimental phase and the definitive entry into force occurred with Law no. 148 of 5 June 1990, whose articles were subsequently incorporated in the Single Text of the School Laws in D.L.vo no. 297/94.

In the general premise there is an explicit reference to the integration of disabled pupils and learning difficulties.

In the 1955 Programs, the terms handicap, diversity, discomfort, inequality are not present, while in the 1985 Programs are dealt with. ${ }^{1}$

The programs of the 1985 are designed so that they constitute a pedagogical document from which civic-social education emerges. The figure of a child emerges from the center of the mind. The criticality of breaking up with the tradition of the unique classmate is also strong for a number of masters.

Subsequently it is important to emphasize C.M. n. 250 of 3 September 1985 which insists on the importance of identifying and analyzing the educational needs of the disabled child, starting from the knowledge of its basic potential. Starting from the Functional Diagnosis developed by the USL team member's medical staff, the school together with the family and social and healthcare professionals must develop the Individual Educational Plan that will be included in classroom educational and teaching programming. This will allow the disabled child to obtain basic operational tools that will evolve in the development of programming properly prepared on its potentialities and attitudes.

For the most disadvantaged children, therapeutic and rehabilitative care interventions are arranged in agreement between USL and school so that more relaxed times can be taken to encourage pupils' learning.

The support teacher's figure thus becomes the point of reference and the mediator between the school, the health care team and the family so that integration, individualized programming, educational and educational interventions are carried out. $^{2}$

In 1986 they were approved by a D.M. The new curricula of the two-year multi-purpose professional training courses for the management staff. Educational and teaching staff dealing with disabled children.

With these new programs of the Specialization Course, a new professional figure of the specialized teacher can be drawn up above all to work in the common school. In addition, these programs were intended to effectively guarantee the principle of polyvalence of the issued title and to reduce the technical and health disciplines in favor of pedagogical and didactic teaching. As far as the structure was concerned, three poles were identified corresponding to a number of key areas for the preparation of the teaching professor. The first, referred to as "Disciplinary Areas", concerned pedagogy, psychology and the clinic, whose programs were subdivided for each of the two years of course. The second pole, called "Operational Dimension", indicated activities aimed at practice and consisted of six areas or sub-areas: observation methodology, functional evaluation, relational dynamics analysis, curricular programming, technology and subsidy strategies, and organizational integration. The third pole, referred to as "Curriculum Didactics", indicated the scope in which it was necessary to find its own implementation of the series of aspects intended to translate the general didactics (considered from the point of view of nursery and compulsory education) in specifically designed didactics Under conditions of disability, particularly visual and auditory. Particularly important was the training that the Commission considered to have to articulate in two major fields to be understood as being integrated and closely linked:

- A direct guided internship that was to take place in the school's reality and to be carried out under proper monitoring. (150 hours per year).

- Indirect and guided training consisting of 100 per year.

The total time of the biennium of specialization was 1300 hours. $^{3}$

\footnotetext{
${ }^{1} \mathrm{http}: / /$ www.integrazionescolastica.it/article/907.

2 B.Orizio, (edited by), Special Pedagogy in Europe.Problematic and Research Status, FrancoAngeli, Milan, 2007.

${ }^{3}$ See L. Trisciuzzi, Teaching Manual ... op. cit.
} 
- The support teacher had to be a multifaceted figure who could deal with the pedagogical and non-rehabilitative pedagogical point of view of all possible disability situations that children could enter in normal classes. ${ }^{1}$

The introduction of the support teacher, despite having been a key element in the integration of children with disabilities in the school, has been affected and continues to suffer from the same difficulties as integration by suffering contradictions in

legislation and ambiguities such as continence In the class that is still not well understood today by curriculum teachers and also with a little recognized professionalism compared to other colleagues.

Without doubt, the support teacher is formed as a mediation between the disabled pupil and the rest of the school, in favour of the child's insertion. ${ }^{2}$

The formation of a support teacher should not be considered as an "addiction" to the general classroom teacher training but must have a well-defined structure with specific skills and we will see how this will evolve over time. ${ }^{3}$

On January 4, 1988, the C.M. n. 1 concerning the issues related to the school continuity of disabled pupils; This topic is also addressed in the socio-sanitary field.

It must be borne in mind that educational continuity presents some difficulties as the child's biological psychological development also has a continuity that can undergo changes. It is therefore important that the support teacher combines the psychological, educational, methodological and didactic skills acquired between one order and the other in the school, for a passage of the pupil with fewer possible difficulties. ${ }^{4}$

In recent years the support teacher's figure is very much debated with regard to his formation, so the D.M. Of 14 June 1988, which again defines the curricula of the polyvalent specialization courses for the training of the teaching staff. Some of the teacher's features are a good methodological preparation and the ability to know how to evaluate, plan, have a good educational training gained through apprenticeship and a highly pedagogical competence. He must also have good communication skills with other colleagues and educators and be a reference point for the educational project of the disabled pupil.

This Decree seeks to highlight how the certified pupil should be included in a project that involves not only the support teacher but also the class teachers and all the other operators so that the pupil and the teacher of Support are not isolated. ${ }^{5}$

In C.M. n. 184 of July 13, 1991, further features of the support teacher profile such as co-operation with colleagues, the class council and the working group are provided to carry out the educational project, the competence to draw up the educational path, responsibility with the Class program colleagues collaborate with families and social and healthcare structures. ${ }^{6}$

It is further specified that support teachers are part of the circular staff and assume ownership and address the issue of derogations for particularly severe handicap cases for which functional diagnosis requires particularly careful and detailed individualization programming.

This circular deals with the following aspects that must characterize the teaching profession: it is required to collaborate with colleagues, with the class council, with the Working Group on the Handicap to draw up the Individual Educational Project of the Disabled; Must have the didactic and educational skills to set up the pupils' school path; Must have the coresponsibility of the class with other colleagues; Is required to maintain collaborative tasks with the USL of the territory belonging to the disabled child and the family. ${ }^{7}$

\footnotetext{
1 V. Piazza, The Supporting Teacher. Technical skills and emotional aspects, Erickson, Trento, 2009.

2 See B Vertecchi, (edited by), The Century of the School .... op. cit.

${ }^{3}$ See P. Bosio I. Menegoi Buzzi, (ed.), School and Diversity in Europe .... op. cit.

${ }^{4}$ See B Vertecchi, (edited by), The Century of the School .... op. cit.

${ }^{5}$ See L. Trisciuzzi, Teaching Manual ... op. cit.

${ }^{6}$ European Agency for Development in Special Needs Education, a study report titled "Organization of Support for Teachers Working on Special Needs in Common Education. Trends in 17 European Countries ", 2003.

${ }^{7}$ A. Lascioli, M. Onder, Teaching in Global Society. What training for teachers in a European perspective ?, ISRE - Journal of Education, Communication and Educational Research, 2010, XVII, n. 3, pp. 31-46.
} 


\section{A look at the inclusion and training of specialized teachers}

From the Study Relationship to the Organization of Support for Teachers Working with Special Needs in Common Education, drawn up by researchers at the European Disability Insurance Agency, the need for support is not only centered on As it requires essays addressed to curricular insiders with the aim of helping them to improve specific treatment skills and management of special educational needs in the classes. ${ }^{1}$

The distinction between ordinary teachers (without specific training on inclusion issues) and specialized teachers (with a specialization degree for support) has generated the distinction between classroom students and students Special students. In fact, reality is very complex and varied, especially if you look at the world of school today. ${ }^{2}$

Here it is found that special subjects also have normal needs and that even regular students may have special educational needs. Ignoring this circumstance leads us to believe that solutions to problems can also follow the same logic, that is, for special pupils extraordinary solutions and ordinary students ordinary solutions.

An incorporated school system can only be created if the common schools become more inclusive. In other words, if they are better in educating all children of their co-existence. ${ }^{3}$

The curriculum of the first-level school teachers was initiated for the first time in 2000-2001, so three years after the D.M. Of 26 May 1998, which provided for the establishment of the Bachelor's Degree in Educational Sciences, in correspondence of the first enrollment of students to the second biennium of the university, with 6 disciplines relating to Special Pedagogy, 6 laboratories, 100 hours Specialized training, of which 50 direct and 50 apprenticeships, all organized in two semesters. Subsequently, changes were made to the curriculum, both in terms of co-op and support, especially with regard to the internship.

Undoubtedly, the support teacher's figure must increasingly respond to the special educational needs that the disabled pupils need, and therefore the initial formulation such as the one in the process becomes more and more important to acquire an adequate professionality.

This course of study has ultimately led to a qualification of the role of primary school teacher and also of support, which had been lost in time, as it allowed those who wanted to undertake this work path to appropriate adequate knowledge in psycho-educational, communicative And relational, increasingly needed to address the problems of all pupils. ${ }^{4}$

On 10 September 2010, the Legislative Decree no. 249 by Minister Gelmini, concerning the definition of the discipline of the requirements and the modalities of the initial training of the teachers of the elementary school and the primary and secondary schools of the first and second grade, radically changing the teacher training system.

The Bachelor of Science in Education, compulsory for the education of primary and secondary school teachers, passes from four to five years in a single cycle.

In the course provided for curriculum teachers, 31 Cfus are required on special educational issues and 75 hours of apprenticeship with disabled pupils. In order to gain support on the support, pending future changes, even teachers who already have the common path, are expected another year of study formed from $60 \mathrm{Cfu}$.

It is an important novelty to foresee in the 31 Cfu study on special educational needs, as just as underlined in framework Law 104/92, the pupil can not belong to the teaching teacher but is included in the class and therefore is of all the teachers as the companions, as in turn the support teacher is contests with the classmates and hence responsible for all pupils.

At present, the support teacher must have an appro priate preparation in the field of pedagogy and special education, must know how to use ICT (information and communication technologies), simulation, observational and experimental methods.

\footnotetext{
1 Unesco, Policy Guidelines on Inclusion in Education, Paris, 2009.

${ }^{2}$ A. M. Favorini, Special Pedagogy and Teacher Training. Towards an Inclusive School, FrancoAngeli, Milan, 2009.

${ }^{3}$ A. Canevaro, L. D'Alonzo, D. lanes, R. Caldin, (eds.), School Integration in Teacher Perception, Erickson, Trento, 2011.

${ }^{4}$ Decree n. 254 | 16/11/2012, National Guidelines for Early Childhood Education Curriculum.
} 
He must be able to promote social relations between the disabled and the rest of his comrades, through communication strategies, psycho-motility, and play activities, and be able to put into practice actions.

The skills required of a teacher are increasingly complex and requires many years of preparation and is constantly being upgraded as the school has a large responsibility in the relationships of its pupils and society. ${ }^{1}$

\section{BES: new training frontier}

A new season of reforms opens in 2012: New Guidelines for the Curriculum for the Children's School and the Early Learning Circuit; And the Ministerial Directive December 27, 2012 Intervention tools for pupils with special educational needs and territorial organization for school inclusion, to which was followed the note prot. 1551 of 27 June 2013 and subsequently the Ministerial Circular no. 8 of March 6, 2013 with the operational guidelines to be able to begin to work more coherently in the Annual Inclusion and Training Scheme (Inclusion Groups) within each school order, so To be able to provide a suitable pathway for the learning of those children that are defined as borderline, or in situations of learning difficulties or hyperactivity which do not fall into any DSM-IV diagnostic category, and that more and more Cause school disruption and consequently have a negative impact on the child's personal condition in the future and further aggravates the social and economic condition of our country.

Referring to the 2007 National Guidelines, we have now reached the current level of 2012, with the definitive text of the National Guidelines for the Curriculum of the Children's School and the Early Learning Circuit, henceforth Guidelines, issued by Decree n. 254 of November 16, 2012. The method adopted for the review, which received the appreciation of the school and the bodies consulted (June-July 2012), represents a major asset to start and creates the conditions for further development.

The New Indications feature a challenging school model, which is a compelling reference point, while respecting the free teaching initiative of teachers and the exercise of the design autonomy of individual schools. Documents, however, do not have an autonomous propulsion, they are likely to remain in the shadows and are not always properly known. Cultural investments must be made on them to seek to achieve that "continuous improvement of teaching", as requested by D.M. 254/2012, Article 3, which establishes a National Scientific Committee (CSN) "in charge of addressing, supporting and enhancing training and research initiatives, in order to increase the effectiveness of teaching in line with the aims and objectives set out In the indications".

The task of CSN, appointed by D.M. Of 19/3/2013, it is therefore mainly to accompany the Guidelines, particularly in their first application phase, so that schools and teachers familiarize themselves with their logic and translate it into everyday teaching practice.

School institutions are not simply called to use and make good use of the Guidelines, but they are required to carry out verification work, critical interpretation, and development of long-range action slopes.

So doing school today means connecting the complexity of radically new ways of learning with a day-to-day running of work, attentive to method, new media, and multi-dimensional research. At the same time, it means curing and consolidating basic skills and knowledge, which are indispensable because they are the foundation for conscious use of widespread knowledge and because they make early learning of all learning opportunities throughout life. And since relations with computer tools are still very uneven both among students and teachers, the learning and retraining skills of teachers and attention to access to new media becomes decisive. The prevalence of motivated, prepared teachers, attentive to the specifics of the children and the groups they care for, is an indispensable quality factor for building a friendly, well-organized, Able to arouse the trust of parents and the community. The teacher's educational style is inspired by criteria of listening, accompaniment, participatory interaction, communitarian mediation, with a continuous observation ability of the child, a causal part of his world, reading his discoveries, support and incapacity for the evolution of his learning towards more and more autonomous and connoisseur forms of co-openness. Design is expressed in the ability to give sense and intent on the interplay of spaces, times, routines and activities, to promote a coherent educational context through an appropriate pedagogical course.

\footnotetext{
${ }^{1}$ Miur Directive of 27/12/2012, "Intervention Tools for Students with Special Educational Needs and Territorial Organization for School Inclusion".
} 
Teacher's professionalism is enriched through work-related work, continuing education, reflection on didactic practice, adult relationship with knowledge and culture. Building a professional, knowledge-intensive, community-based community is stimulated by the leadership leadership role and by the presence of forms of pedagogical coordination. ${ }^{1}$

The Ministerial Directive on BES on 21/11/2012 and then the Ministerial Circular on 22/11/2013 made explicit everything that teachers experience on a daily basis, ie the accentuated differentiation of the pupils present In the various classes that is not due solely to the presence of disability, disturbances in learning or the placement of pupils who are immune; The purpose of the Mixture Directive was to underscore the fact that there may be in our classes any school order with Special Needs, regardless of the condition of being certified rather than migrant.

In this way the focus shifted from the purely diagnostic dimension to the needs of the pupils and their well-being, which can be limited in time, as time-waning conditions, as they can be persistent over the years, and May therefore require special attention from the teachers precisely because they are dealing with Special Educational Needs to encourage the learning of the children themselves. Among other things, the normative reference issued by the Ministry also uses the school dropout rate that we are still at a relatively high level compared to other European countries, which unfortunately aggravates the social condition of our country as well as To the personal one. It is to be said, however, that as every novelty has caused countless criticisms, both by the teaching staff of every school order and the point of view of scientific co-existence, particularly from the category of Special Pedagogues of the various Italian Universities.

The opposite interpretations of the Directive oscillate between the thesis of unfair medicalization of many pupils and the argument for the adoption of the Diagnostic Model of the International Classification of Functioning (ICF) of the World Organization of Health.

It should also be noted, however, that in this legislation there is much more than legislative aspect, as in recent years we have always been noted in the various circles or laws as a bio-psycho-social approach since the ICF model from the mo This is based on the context analysis and the operating profile, in order to identify the BES without precluding typing. ${ }^{2}$

In fact, in the school the teacher does not respond solely to himself and to his or her own. All the teachers are called together to build a coherent and unified project.

It is a complex and challenging work that sets in motion a dense network of relational dynamics and can not escape the conflict. Conflict, however, must not necessarily be lived in the negative, is part of life, is an element of enrichment if one can process it positively and remain in terms of social acceptability. It is an opportunity for growth and often allows a synthesis of ideas for better solutions. Collegiality in the exercise of the teaching function is one of the characteristics of today's school.

The transition from the classroom teacher to the primary school to the teaching group changed the professional model of the single teacher, who was responsible for his students. The teaching team, of which the support teacher is a full member, must be a collegiate system in which each member performs tasks, assumes specific functions, in the sense of coresponsibility and sharing.

The support teacher must have an indispensable ability, which would be the patrimony of all school teachers of every grade, that of being able to collaborate. It is crucial to learn from other people's experiences; Share and confront the frustrations that many times the job can afford; To be able to help curriculum teachers understand both the potential of a disabled learner and children and girls who experience learning difficulties or discomfort.

It is equally important that support is translated into a prevalent individual activity for people with disabilities. In the experience often there are support teachers coming out of the classroom with the disabled pupil, who spend much of the school time.

The "personalization" of educational and didactic action should not be separated from "socialization" with all the resulting clarifications and mediations. It would be desirable to increase the support of teaching staff, through the enhancement of

\footnotetext{
1 D. lanes, The Evolution of the Supporting Teacher. Towards an Inclusive Didactics, Trento, Erickson, 2015

2 R. Caldin, The debate on "Good School" in Thinking the School in Today's Society. Teacher Training, Pedagogy Today, vol. 2-2015
} 
the best skills for coaching and tutoring. Initial training for all teachers capable of providing educational and teaching skills appropriate to ensuring a qualified job with diversity.

A more explicit integrated programming of services, actions, and interventions to transform school integration into the problem of the teacher as a problem for the entire school and social community.

The support teacher needs to know more than other teachers, as Roberta Caldin says, is an added value in the school, with skills and experiences to be put into practice with all pupils.

After this reflection, we analyze the recent situation that is outlining about the training of curricular and supportive teachers.

\section{New perspectives for specialized teachers}

A strong university specialization is needed to become a specific professional figure in all respects, who is steadily active in that role, guaranteeing continuity and not just a transitory function linked to a disabled individual. In perspective, one should speak of a variety of teacher specializations, on various educational, educational and organizational issues. A university specialization is based on the previous university course, and should articulate on the skills acquired for the first level degree. In recent years, we have been very much concerned about the skills of integrating and inclusion that each teacher should have at the end of his initial training course, but there are many differences between universities, depending on their importance attributed to inclusive processes.

The Law 107/2015 delegates to the Government to legislate on the initial training of future curricular and specialized teachers while addressing the theme of on-service training, continuous and mandatory for all teachers, with emphasis on more careful training in ' Inclusion and disability. As indicated by each school institution in accordance with the Triennial Training Offer Plan, and with the results of the Improvement Plan, training courses are set up within the institution, by virtue of school autonomy.

The schools in the coming years through the good use of Triennial Training Offer Plans will have the opportunity to organize more flexibly to their needs, their pupils and their own territory by building project and laboratory pathways, adapting to the needs of all pupils.

Legislative Proposal C-2444, Rules for Improving the Quality of Inclusion of Pupils with Disabilities and Other Special Educational Needs submitted to the House by FISH and FAND, envisages deeply different university training courses to become specialized teachers As opposed to becoming curricular teachers. According to this proposal, primary and primary school teachers after the first three common years should attend a specific two-year period to become specialized teachers, for secondary school teachers after the three-year degree they would have a master degree on support. ${ }^{1}$

As a support teacher, I believe, as many Special Education Professors who have expressed themselves in this regard in various SIPeS documents, that such a deep distinction in the university course can only lead us away from the path of inclusion of pupils with disabilities instead to favour it.

Recent Italian and international literature indicates that it is necessary to value the "functioning" of people with disabilities: in this sense, the training courses of the specialized teachers for support would therefore be foreseen through in- depth studies on school enrollment and education, Social inclusion, with a positive outlook highlighting the potential rather than the deficits by resorting to "specific mediators" (people and tools) that can support common and shared community-class activities.

Teacher specialization should not address issues such as those related to individual pathologies, as suggested by Law C2444; These pathologies are different and always evolving: the figure of the specialist teacher for support activities is surely evolving and different ways may be the way to go, but it is indispensable that they are all in favor of inclusion and not in the direction of a Specialization closer to the medical one, as can be the case when it comes to "pathologies". It is likely that children with disabilities, in a school that promotes skills and develops a targeted curriculum, need specific attention in the learning process.

${ }^{1}$ Online marketing form through web site optimization for search engines like Google, Bing, Yahoo etc. 
The training currently provided through the annual specialization courses for support provides a sufficient amount of hours to train a good teacher capable of delivering significant and significant responses also to people with severe disabilities. $\dot{E}$ It is imperative to create a continuous training system, capable of periodically offering service support teachers, modules and university courses able to update their special pedagogical knowledge. It is therefore proposed that the University organizes second-level Master's degrees that can complete the multi-faculty training of the specialized teacher for support (eg, with regard to sensory, behavioral, cognitive disabilities) and innovative methodologies. Their university education in the three-year course and in the course of the master degree $(+2)$ they can benefit from modules and lessons aimed at special 60-credit basic training, capable of providing their professional background with educational skills that are appropriate to ensure a qualified job with disabled people. ${ }^{1}$

At the heart of everything there are pupils, so it is crucial that the debate on the formation of future teachers be pursued by pursuing the purpose of inclusion, no one excluded.

\section{Bibliography}

[1] P. Bosio, I. Menegoi Buzzi (ed.), School and Diversity in Europe. Teacher Training Tools on Integrating Disabled in School, FrancoAngeli, Milan, 2005.

[2] http://www.integrazionescolastica.it/article/907

[3] R. Caldin, The debate on "Good School" in Thinking the School in Today's Society. Teacher Training, Pedagogy Today, vol. 2-2015.

[4] N. D'Amico, History and stories of the Italian school. From Origins to Today, Zanichelli Editore, Bologna, 2010.

[5] Decree n. 254 | 16/11/2012, National Guidelines for Early Childhood Education Curriculum.

[6] Miur Directive of 27/12/2012, "Intervention Tools for Students with Special Educational Needs and Territorial Organization for School Inclusion".

[7] European Agency for Development in Special Needs Education, a study report titled "Organization of Support for Teachers Working on Special Needs in Common Education. Trends in 17 European Countries ", 2003.

[8] M. Favorini, Special Pedagogy and Teacher Training. Towards an Inclusive School, FrancoAngeli, Milan, 2009.

[9] D. lanes, The Evolution of the Supporting Teacher. Towards an Inclusive Didactics, Trento, Erickson, 201.5

[10] Lascioli, M. Onder, Teaching in Global Society. What training for teachers in a European perspective ?, ISRE Journal of Education, Communication and Educational Research, 2010, XVII, n. 3, pp. 31-46.

[11] Orizio, (edited by), Special Pedagogy in Europe. Problems and Status of Research, FrancoAngeli, Milan, 2007.

[12] V. Piazza, The Supporting Teacher. Technical skills and emotional aspects, Erickson, Trento, 2009.

[13] L. Trisciuzzi, The integration of the disabled into the compulsory school. An Alternative Didactic Proposal, Lisciani \& Giunti Editore, Teramo, 1980.

[14] L. Trisciuzzi, Handbook for Handbook, Laterza, Bari, 2010.

[15] UNESCO, Policy Guidelines on Inclusion in Education, Paris, 2009.

[16] Vertecchi, (edited by) The Century of the School: Education of the Twentieth Century, New Italy, Florence, 1995

${ }^{1}$ The online marketing form of search engines like Google, Bing, Yahoo etc. 